\title{
Быстродействующие болометрические матричные детекторы
}

\author{
Р.3. Хафизов, В.В. Старцев, В.Ю. Москвичев \\ Акционерное общество «Оптико-механическое конструкторское бюро «АСТРОН», \\ Московская область, г. Лытккарино, 140080, ул. Парковая, 1 \\ тел./факс: +7 (495) 941-6272, эл. почта: v@astrohn.ru
}

DOI 10.34077/RCSP2021-159

Для развития неохлаждаемых болометрических быстродействующих матричных детекторов в применениях, где требуется фиксация быстроизменяющихся событий, например, для пеленгации быстродвижущихся тепловых объектов, были рассмотрены возможности оптимизации параметров и характеристик матричных неохлаждаемых микроболометрических фотоприемных устройств (ФПУ), выпускаемых «ОКБ «Астрон». Нами определены конструктивные и технологические решения по их разработке, направленные на реализацию требований по функционированию перспективных ОЭС. $[1,2]$

Рассмотрение проведено в рамках общепринятой теории поглощения ИК излучения и теплофизических процессов, протекающих в мембранных МЭМС-структурах. Представлены результаты их моделирования, позволяющие провести оптимизацию конструкции и ее реализации с использованием современных технологических процессов формирования высокоэффективных микроболометрических элементов с учетом требований конкретных применений.

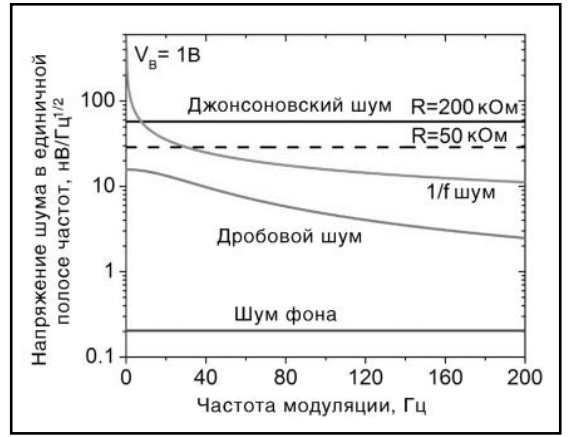

Рис. 1. Напряжение шума в единичной полосе частот для основных типов шумов болометрического сенсора в зависимости от частоты модуляции при смещении $1 \mathrm{~B}$

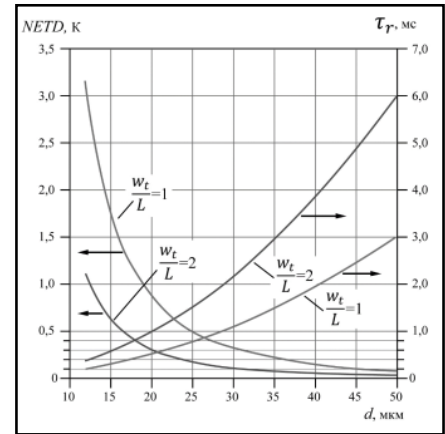

Рис. 2. Зависимость NETD от шага элементов

При конструировании матричного болометрического приёмника изображения в качестве основных задаются: количество $\mathrm{N}$ и шаг $\mathrm{d}$ следования элементов матрицы, определяющие требуемое пространственное разрешение, время кадра, задающее временно́е разрешение, и чувствительность в терминах эквивалентной шуму разности температур (NETD-Noise Equivalent Temperature Difference) прибора. [3]

В работе рассмотрены теоретические соотношения, оптимизирующие конструкцию микроболометрического элемента матричного детектора, обеспечивающие улучшение его характеристик быстродействия с учетом конкретных применений. Сформулированы требования к параметрам элементов и используемых для его изготовления материалов, которые предоставляют принципиальную возможность минимизации времени тепловой релаксации болометрического сенсора с целью увеличения кадровой частоты.

\section{Jumepamypa}

[1] S. Tinnes, N. Boudou, A. Durand, Ulis Bolometer Improvements for Fast Imaging Applications, OECD Conference Center, Paris, France / 6 - 8 February, 2018.

[2] С. А. Демин, Б. В. Трошин, С. А. Жукова, В. Е. Турков, Быстродействующий широкодиапазонный инфракрасный микроболометрический детектор, Патент RU 2574524C1, 15.12.2014.

[3] E. M. Smith et el, Enhanced performance of VOx-based bolometer using patterned gold black absorber, Proceedings of SPIE Vol.9451, pp 94511I-1-94511I-7, 2015, doi: 10.1117/12.2177401. 